OPEN ACCESS

Edited by:

Steven Foung,

Stanford University, United States

Reviewed by:

Jean Dubuisson,

Centre national de la recherche scientifique (CNRS), France

Brian G. Pierce,

University of Maryland, College Park,

United States

*Correspondence:

Yimin Tong

ymtong@sibs.ac.cn;

Jin Zhong

jzhong@ips.ac.cn

Specialty section:

This article was submitted to

Vaccines and Molecular

Therapeutics,

a section of the journal

Frontiers in Immunology

Received: 20 April 2018

Accepted: 06 June 2018

Published: 19 June 2018

Citation:

Tong Y, Lavillette $D, L i Q$ and Zhong J

(2018) Role of Hepatitis C Virus

Envelope Glycoprotein E1 in Virus

Entry and Assembly.

Front. Immunol. 9:1411.

doi: 10.3389/fimmu.2018.01411

\section{Role of Hepatitis C Virus Envelope Glycoprotein E1 in Virus Entry and Assembly}

\author{
Yimin Tong ${ }^{1 *}$, Dimitri Lavillette ${ }^{2,3}$, Qingchao Li $^{1,3}$ and Jin Zhong ${ }^{1,3 *}$ \\ ${ }^{1}$ Unit of Viral Hepatitis, CAS Key Laboratory of Molecular Virology and Immunology, Institut Pasteur of Shanghai, Chinese \\ Academy of Sciences, Shanghai, China, ${ }^{2}$ Unit of Interspecies Transmission of Arboviruses and Antivirals, CAS Key \\ Laboratory of Molecular Virology and Immunology, Institut Pasteur of Shanghai, Chinese Academy of Sciences, Shanghai, \\ China, ${ }^{3}$ University of Chinese Academy of Sciences, Beijing, China
}

Hepatitis C virus (HCV) glycoproteins E1 and E2 form a heterodimer to constitute viral envelope proteins, which play an essential role in virus entry. E1 does not directly interact with host receptors, and its functions in viral entry are exerted mostly through its interaction with E2 that directly binds the receptors. HCV enters the host cell via receptor-mediated endocytosis during which the fusion of viral and host endosomal membranes occurs to release viral genome to cytoplasm. A putative fusion peptide in E1 has been proposed to participate in membrane fusion, but its exact role and underlying molecular mechanisms remain to be deciphered. Recently solved crystal structures of the $\mathrm{E} 2$ ectodomains and $\mathrm{N}$-terminal of $\mathrm{E} 1$ fail to reveal a classical fusion-like structure in HCV envelope glycoproteins. In addition, accumulating evidence suggests that E1 also plays an important role in virus assembly. In this mini-review, we summarize current knowledge on HCV E1 including its structure and biological functions in virus entry, fusion, and assembly, which may provide clues for developing HCV vaccines and more effective antivirals.

Keywords: hepatitis C virus, envelope protein, E1, virus entry, virus assembly, fusion

\section{INTRODUCTION}

Hepatitis $\mathrm{C}$ virus $(\mathrm{HCV})$ is a major human pathogen that currently infects about 170 million people worldwide. Although recent introduction of highly effective direct-acting antiviral agents has greatly improved hepatitis $\mathrm{C}$ treatment outcome, no prophylactic $\mathrm{HCV}$ vaccine is available, rendering it difficult to eradicate HCV infections globally $(1,2)$. HCV is an enveloped, positive-strand RNA virus belonging to the family of Flaviviridae. The HCV RNA genome is $9.6-\mathrm{kb}$ in length and encodes a single polyprotein that is co- or post-translationally cleaved into three structural proteins (core, $\mathrm{E} 1$, and E2) and seven non-structural proteins (p7, NS2, NS3, NS4A, NS4B, NS5A, and NS5B) (1). The envelope glycoproteins E1 and E2 form a stable heterodimer that mediates virus entry and morphogenesis. HCV virions are associated with host low-density lipoproteins or very-low-density lipoproteins, which play important roles in virus entry, egress, and evasion of the host immune response (3). HCV entry and morphogenesis are highly coordinated processes, which involve all viral structural and non-structural proteins as well as a panel of host factors (4-6). Here, we aim to

Abbreviations: HCV, hepatitis C virus; HCVpp, HCV pseudoparticle; HCVcc, cell-culture derived HCV; CLDN1, claudin-1; $\mathrm{nE1}$, N-terminal domain of E1; pFP, putative fusion peptide; C, cysteine; Asn, asparagine; TMD, transmembrane domain. 
summarize current knowledge of HCV E1 including its structure and biological functions in virus entry and morphogenesis.

\section{STRUCTURE OF E1}

\section{Domains/Motifs Organization}

E1 envelope glycoprotein (192 amino acids) is much smaller than E2 (approximately 365 amino acids depending on the genotypes) but both are type I transmembrane protein with the $\mathrm{N}$-terminal ectodomain residing in the endoplasmic reticulum (ER) lumen and the C-terminus anchoring on the ER membrane. The length of HCV E1 and E2 is similar to that of pestivirus E1 and E2, but many other flaviviruses only encode a single envelope glycoprotein E of 500 amino acids. Bioinformatics analysis of E1 sequences across all genotypes reveals a conserved protein domain organization, including N-terminal domain (NTD, 192-239), putative fusion peptide (pFP, 272-285), conserved region (CR, 302-329), and C-terminal transmembrane domain (TMD, 350-381) (Figure 1). NTD contains four conserved cysteines that form intramolecular, and possibly intermolecular, disulfide bonds. In addition, majority of E1 glycosylation sites and identified E1 epitopes reside in this domain, suggesting NTD is likely exposed on the protein surface. The exact roles of NTD remain elusive, although it was shown that a motif (aa 219-221) in NTD may have a cross talk with TMD to determine the complex formation with E2 (7). TMD, also serving as the signal peptide for $\mathrm{E} 2$, dictates membrane-bound topology of E1 and is essential for forming a heterodimer with E2. pFP is highly conserved and has been proposed to participate in fusion of viral envelope and host cell membrane during HCV entry $(5,8)$. CR is highly conserved among all genotypes/subtypes, but its function is poorly defined.

\section{Glycosylation}

Both E1 and E2 are heavily glycosylated, and N-linked oligosaccharides are added to asparagine (Asn) within the context sequon Asn-X-Ser/Thr (16). E1 of major genotypes possesses four conserved potential N-linked glycosylation sites (196, 209, 234, and 305) (17), while the fifth glycosylation site at N250 is only specific to genotypes $1 \mathrm{~b}$ and 6 (18). E1 is not efficiently glycosylated if expressed alone, and requires the co-expression of E2 protein for the full-extent glycosylation (16).

E1 glycosylation contributes to correct protein folding and its biological functions. An early study showed that mutation of N196 or N305 impairs the E1/E2 heterodimerization while mutation of N209 or N234 has little effect (17). A later study based on HCV pseudoparticles (HCVpps) confirmed that glycosylation at N196 or N305 is critical for E1 folding and its incorporation into HCVpp, whereas N209 may modulate the virus entry (19). Using cell-culture derived HCV (HCVcc) system, it was shown that N196 is the most critical among the four E1 glycosylation sites for the HCVcc infectivity (20). In addition, E1 glycosylation pattern may regulate the formation of disulfide bond in E1. For example, disulfide bond involving C306 will likely be prevented by glycosylation at N305 due to spatial restriction (17). Interestingly, removal of this glycosylation increases the immunogenicity of soluble E1 (21). Another study also found that removal of the glycan at N209 improves immunogenicity of the E1/E2 heterodimer (22).

\section{Disulfide Bonds}

Eight cysteine residues (C207, C226, C229, C238, C272, C281, C304, and C306) are highly conserved across all HCV genotypes. Although extensive analyses have been performed to decipher the possible disulfide bond matches among these cysteines, these efforts only yielded limited and conflicting information thus far. The solved partial E1 crystal structure revealed an intramolecular disulfide bond between C229 and C238 as well as an intermolecular disulfide bond between C207 and C226 (23). However, this finding is contrasted by another structure modeling study suggesting C226 remains in a free thiol state (24). Instead, this study proposed three different intramolecular disulfide bonds C207-C306, C229-C304, and C238-C281 (24). Moreover, possible disulfide bonds between E1 and E2 have also been proposed based on the proximity of cysteines in the predicted E1/E2 structures, such as C272 (E1) and C452 (E2), C304 (E1), and C486 (E2) $(24,25)$. These conflicting reports not only reflect the technical difficulty to determine the existence of disulfide bonds but also may reflect the complexity in dynamic changes of disulfide bond formation in E1 during the processes of HCV entry and morphogenesis. Indeed, virion-associated E1 and E2 envelope glycoproteins formed large covalent complexes stabilized by disulfide bridges, whereas the intracellular forms of these proteins assembled as noncovalent heterodimers (26). In addition, C226-C229 form a classical CxxC motif, a key feature of protein disulfide isomerase, which may mediate the isomerization of disulfide bonds in E1 during virus entry $(24,27)$, as reported in Env fusion proteins from retroviruses $(28,29)$. More experiments are needed to validate this hypothesis, as reports using thiol-reactive agents indicated that HCV entry is weakly dependent on its redox status, in contrast to other enveloped viruses (30). Mutagenesis of the eight conserved cysteines in E1 indicated that, unlike cysteine mutations in E2 that drastically disrupt virus infectivity (31), the cysteine mutations in E1 have much less effect on virus infectivity (27). Interestingly, the E1 cysteine mutant viruses hardly survive from the freeze-thaw treatment that normally does not harm wild-type HCVcc, suggesting that the disulfide bonds in $\mathrm{E} 1$ are more flexible but critical for maintaining stability of infectious virions (27).

\section{Crystal Structure}

The NMR structures of partial E1 domains are available, including the region 314-342 (structure 2KNU) (32) that overlaps with the CR domain, and the region 350-369 (structure 1EMZ) (33) that resides in the TMD. The crystal structure of N-terminal domain of E1 (192-270, nE1) was recently solved (23). The $\mathrm{nE} 1$ monomer structure contains an $\mathrm{N}$-terminal $\beta$-hairpin, a 16 amino acid $\alpha$-helix in the middle and a three-strand antiparallel $\beta$-sheet in the C-terminal. Six nE1 monomers form an asymmetric unit, stabilized by a series of intra- and intermolecular disulfide bonds. Given that the nE1 crystals were prepared at a low $\mathrm{pH}$ condition, the covalently linked $\mathrm{nE} 1$ dimer may represent the post-attachment conformation of $\mathrm{E} 1$ formed in an acidic endosomal compartment. Interestingly, the six-stranded 


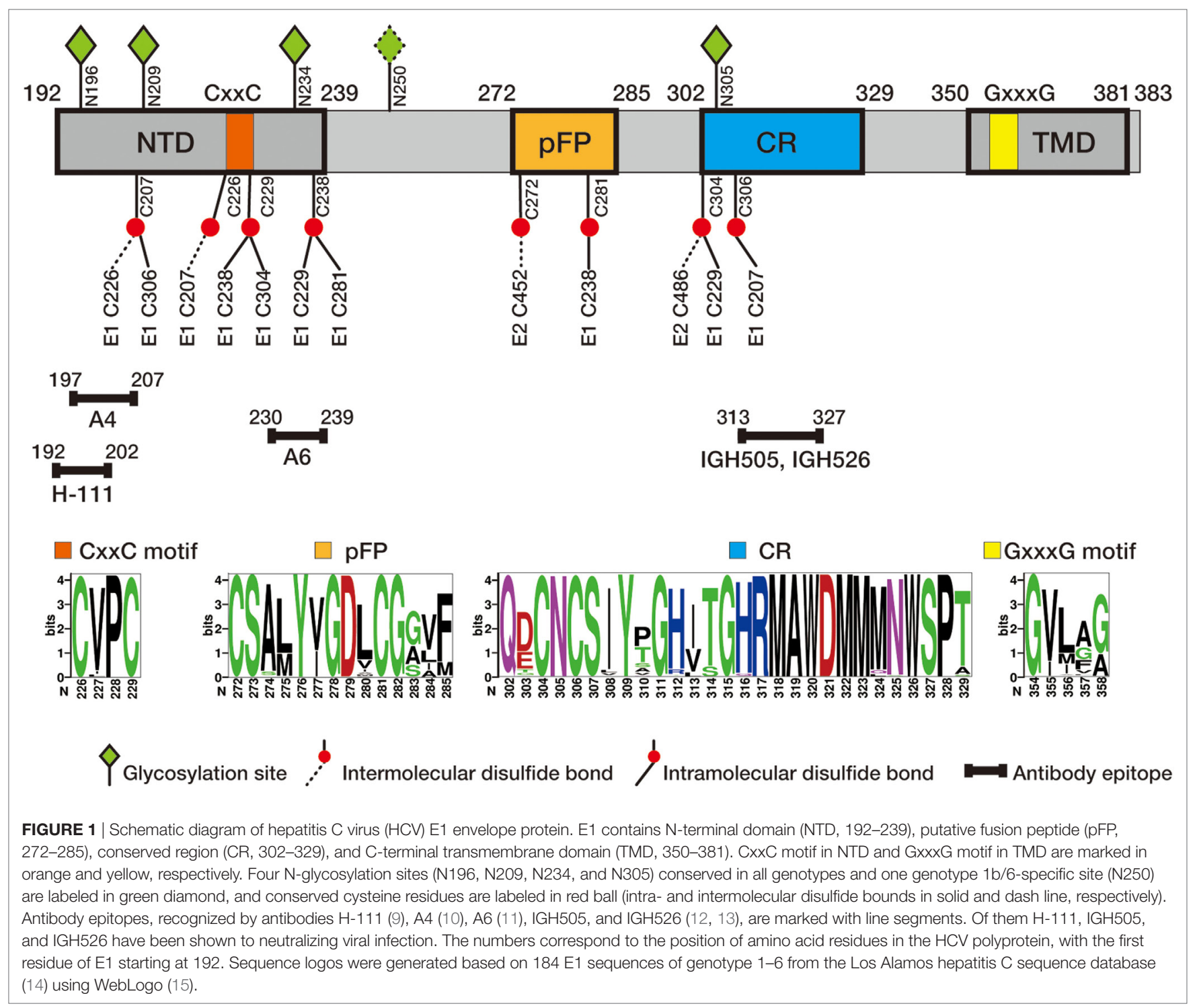

$\beta$-sheet structure formed by the $\mathrm{nE1}$ homodimers appears similar to that of phosphatidylcholine transfer protein (23), raising a possibility that this domain may be one of the structural elements of HCV envelope proteins to mediate the lipoprotein association during $\mathrm{HCV}$ morphogenesis. Unfortunately, this solved nE1 structure gave little structural insight into membrane fusion as the majority of $\mathrm{pFP}$ was missing in the structure. The authenticity of this truncated E1 structure still needs to be validated experimentally, and future efforts should be focused on analysis of the full-length E1 ectodomain structure and E1 structure in complex with E2.

\section{E1 Oligomer and E1E2 Heterodimer}

Oligomeric status of the global HCV envelope protein complex may fluctuate during the $\mathrm{HCV}$ replication cycle. Using HCVcc system, it was shown that trimeric E1 can be detected at the surface of virions by SDS-PAGE under reducing and mild thermal denaturation conditions (34). The formation of trimeric E1 requires the co-expression of $\mathrm{E} 2$, and the $\mathrm{C}$-terminal TMDs on the both E1 and E2 appear sufficient to trigger the E1 trimerization. The highly conserved GxxxG motif (Gly354 and Gly358) located in the N-terminal of E1 TMD is critical for the formation of the E1 trimer (34). Interestingly, unlike the trimeric E1, E2 remains a monomer in SDS-PAGE under the same mild thermal denaturation condition. A working model proposes that the TMDs of three E1 monomers form a trimer in the center and simultaneously interact with the TMD of peripheral E2 to form a heterodimer $(24,34)$. It is unclear whether the conformation of trimeric E1E2 heterodimers is unique to the mature viral particles since this thermal-instable E1 trimer can be also detected in the lysate of infected cells (34).

Expression of E1 and E2 alone can lead to formation of a noncovalent heterodimer, which is retained in the ER inside the cell $(35,36)$. E1/E2 heterodimerization is critically dependent on interaction between their TMDs which consist of a single $\alpha$-helix $(33,35,37)$. 
Truncation or mutation in this $\alpha$-helix abolishes heterodimerization (38). The result of alanine scanning assay demonstrated that the TMDs consist of charged residues in their centers that act as ER retention signals and are directly involved in heterodimerization $(39,40)$. Mutagenesis studies show that the residues G354, G358, and Lys 370 in N-terminal of E1 TMD are essential for heterodimerization $(33,41)$.

\section{THE ROLE OF E1 IN ATTACHMENT AND BINDING DURING VIRUS ENTRY}

Hepatitis $\mathrm{C}$ virus envelope glycoproteins bind to specific proteins at the surface of hepatocytes to initiate the entry process. This process involves a surprisingly large number of host receptors/ co-receptors/factors, and also confers the major determinant of viral tropism (4). These host receptors/co-receptors/factors have been well summarized by recent reviews $(2,4-6)$. Of them, scavenger receptor BI (SR-BI), cluster of differentiation 81 (CD81), and two tight junction proteins claudin-1 (CLDN1) and occludin 1 (OCLN) play the most critical role in HCV entry, and thus are regarded as the real viral receptors/co-receptors. A recent single viral particle imaging analysis on the polarized cell culture revealed a sequential engagement of these receptors/ co-receptors during HCV entry which involves the translocation of HCV from the initial contact site on the basolateral membrane to the tight junction (42).

$\mathrm{E} 2$ is the major HCV envelope protein that directly interacts with the receptors/co-receptors. The physical interactions between E2 and CD81, SR-BI have been biochemically demonstrated, sometime even in the absence of E1 $(43,44)$. It is long believed that the role of $\mathrm{E} 1$ in this process is mainly to assist $\mathrm{E} 2$ by maintaining a functional E2 conformation required for the receptor binding. Indeed, it was showed that the E1E2 complex can interact with CLDN1 whereas E2 alone cannot (45). Consistently, two independent studies showed that mutations in E1 can shift the usage of HCV entry factor from CLDN1 to CLDN6 $(46,47)$, highlighting the importance of $\mathrm{E} 1$ in interaction with CLDN1 during HCV entry process. Furthermore, a critical cross talk between E1 and E2 was identified to modulate E1E2 binding to HCV entry receptors SR-BI and CD81 (45). Interestingly, recent studies suggested that the role of $\mathrm{E} 1$ in virus attachment and binding appears more than just assisting E2. A study showed that E1, but not E2, binds ApoE and $\mathrm{ApoB}$, the apolipoproteins that are decorated on $\mathrm{HCV}$ virions and are crucial for HCV entry through low-density lipoprotein receptor (48). However, this observation was contradicted by a later study showing that E2 instead of E1 interacts with ApoE (49). Another study showed that E1 directly binds CD36 to facilitate HCV attachment (50).

\section{THE ROLE OF E1 IN MEMBRANE FUSION}

Endocytosis takes place upon the engagement of HCV envelope proteins with the receptors. It is well believed that the acidic environment in endosome activates the conformational changes of the envelope proteins and triggers the fusion of viral lipid envelope and endosomal membrane, leading to release of HCV RNA genome to cytoplasm (51). Despite extensive research, the molecular mechanism underlying the membrane fusion during $\mathrm{HCV}$ entry remains obscure. For a long time, the key unanswered questions were which viral protein(s) serve the fusion function and how the E1E2 heterodimer changes the conformation to induce membrane fusion.

The E glycoprotein of flaviviruses, a well-characterized prototype of class II fusion protein, consists of three distinct domains (DI, DII, and DIII), containing a fusion peptide buried at the dimer interface at neutral $\mathrm{pH}(8)$ and carrying both binding and membrane fusion properties (6). HCV E2 was initially considered as the viral fusion protein because of its size as well as its major role in receptor binding. However, the recent solved HCV E2 core structure exhibits a compact and Ig-like pattern $(52,53)$, which is different from any class II viral fusion protein-like structures shared by other flaviviruses (8), ruling out the possibility that E2 alone serves as fusion protein. This was further supported by the resolution of E2 structure of BVDV-1, a pestivirus member of the Flaviviridae family $(8,54)$.

It is now believed that E1 of BVDV and HCV serves as the fusion protein. E1 contains a conserved hydrophobic sequence (CSALYVGDLC, residues 272-281), which has been proposed to be a pFP (55). A number of studies demonstrate that this domain is indeed involved in the HCV fusion process (56-61). In addition, E1 can form a trimer, a typical structure of all fusion proteins. However, E1 seems too small to have a known class II or class III fold that could connect cellular and viral membranes after the fusion peptide insertion. Therefore, HCV E1 may define a new class of membrane fusogen. Interestingly, E1 of Rubella virus in the Togaviridae family does not possess the structural features of a classic class II fusion protein, while E1 of alphaviruses in the same Togaviridae family harbors a typical class II fusion protein (62). We speculate that constraints on flaviviruses or alphaviruses imposed by alternating life cycles between vertebrates and arthropods may result in more conservative evolution of their fusion proteins than for hepacivirus and rubivirus that infect human only. In the absence of this constraint, the structure of HCV or Rubella virus E1 may have evolved a number of specific features, placing it apart from classical class II fusion proteins of known structure.

Rather than being mediated by a single glycoprotein, HCV fusion appears to be mediated by complex intra- and intermolecular E1E2 dialogs that shape structural and conformational rearrangements of the heterodimer complex, similar to rubivirus and alphavirus (63). Consequently, the characterization of interplays between E1 and E2 is critical to decipher the HCV fusion (45). By combining computational analysis and wet-lab data, it was suggested that E1 co-evolves with the Back Layer domain (BL) of E2, and this genetic association is critical for membrane fusion (64). A soluble BL-derived polypeptide inhibits fusogenic rearrangements and $\mathrm{HCV}$ infection, suggesting E1 and E2 BL/ Stem regions govern HCV fusion in a concerted manner (64).

\section{THE ROLE OF E1 IN HCV MORPHOGENESIS}

Compared to virus entry, much less studies have been conducted to address how E1 contributes to HCV morphogenesis. It is believed that the formation of E1E2 heterodimer is a prerequisite 
for assembly of $\mathrm{HCV}$ virion. Any mutations that interfere with the dimerization of E1 and E2 would have a severe impact on $\mathrm{HCV}$ morphogenesis. For example, the mutations in the GxxxG motif located in TMD of E1 can disrupt the trimerization of E1 and formation of the E1E2 heterodimer, which further prevents the assembly of appropriate tertiary and quaternary structures $(25,34)$. In addition, E1 and E2 in virions are linked covalently by disulfide bridges (26), suggesting that HCV envelope proteins undergo conformational changes involving disulfide bond modification during virus assembly process.

E1 or the E1E2 complex can interact with NS2 $(65,66)$, the master viral protein that interacts with multiple viral structural and non-structural proteins to coordinate HCV assembly. This raises a possibility that E1 directly contributes to HCV morphogenesis in a way that may not involve E2. A mutation D263A in E1 abolishes the viral infectivity and leads to secretion of viral particles devoid of genomic RNA (47). Because the direct contact of E1 and viral genome is unlikely, it is tempting to speculate that E1 may regulate the assembly of infectious virions through its interaction with other viral proteins such as NS2.

We recently developed a trans-complementation-based HCV reverse genetics model in which the coding sequence for E1 or E1E2 is deleted from the HCV genome and is provided in trans $(57,67)$. This system allows to perform the mutagenesis study to explore the functional role of individual domains/motifs in the envelope proteins without potential unwanted cis-effects to virus infection by the introduced mutations in the viral RNA genome. By using this system, we found that the pFP in E1 plays an important role in virus morphogenesis in addition to its well-known contributions to HCV entry (57). The deletion of pFP has no effect on the E1E2 heterodimerization, but completely abolishes the production and release of infectious virions. Alanine scanning analysis identified several point mutations within $\mathrm{pFP}$ that specifically affect virus morphogenesis rather than virus fusion (57). These results suggest that the pFP of E1 plays a dual role in virus entry and morphogenesis. More systematical studies are needed to reveal the exact underlying molecular mechanisms and also to investigate the contribution of other domains.

\section{REFERENCES}

1. Li D, Huang Z, Zhong J. Hepatitis C virus vaccine development: old challenges and new opportunities. Nat Sci Rev (2015) 2:285-95. doi:10.1093/nsr/nwv040

2. Ogden SC, Tang H. The missing pieces of the HCV entry puzzle. Future Virol (2015) 10:415-28. doi:10.2217/fvl.15.12

3. Felmlee DJ, Hafirassou ML, Lefevre M, Baumert TF, Schuster C. Hepatitis C virus, cholesterol and lipoproteins - impact for the viral life cycle and pathogenesis of liver disease. Viruses (2013) 5:1292-324. doi:10.3390/v5051292

4. Ding Q, von Schaewen M, Ploss A. The impact of hepatitis C virus entry on viral tropism. Cell Host Microbe (2014) 16:562-8. doi:10.1016/j.chom.2014. 10.009

5. Douam F, Lavillette D, Cosset FL. The mechanism of HCV entry into host cells. Prog Mol Biol Transl Sci (2015) 129:63-107. doi:10.1016/bs.pmbts.2014.10.003

6. Lindenbach BD, Rice CM. The ins and outs of hepatitis $\mathrm{C}$ virus entry and assembly. Nat Rev Microbiol (2013) 11:688-700. doi:10.1038/nrmicro3098

7. Maurin G, Fresquet J, Granio O, Wychowski C, Cosset FL, Lavillette D. Identification of interactions in the E1E2 heterodimer of hepatitis $\mathrm{C}$ virus important for cell entry. J Biol Chem (2011) 286:23865-76. doi:10.1074/jbc. M110.213942

\section{CONCLUSION AND PERSPECTIVES}

Hepatitis C virus entry and assembly are complicated process that involves numerous viral proteins and host factors, including $\mathrm{E} 1$ and $\mathrm{E} 2$. As the conformations of E1 and E2 are interdependent, the functional analysis of each of these two envelope proteins should be always put in the context of the heterodimer. For example, the Ig-fold $\beta$-sandwich structure of E2 ectodomain displays similarities with domain III class II fusion proteins (53), suggesting that E2 may serve as a chaperone protein for E1 folding to assist its function in virus fusion. Thus, if we regard the E1/ E2 complex as an integrated functional protein, their functions may become easier to understand and characterize.

Compared to E2, E1 is less immunogenic. It is probable that most E1 domains are hidden in the E1E2 heterodimer. However, during the heterodimer conformational changes in virus entry process, some E1 domains must be unmasked to finalize the fusion process. Therefore, the characterization of these dynamically exposed E1 domains, such as structural resolution of the E1E2 complexes in their pre- and post-fusion states, should be the keys to fully understand the roles of E1 in HCV life cycle and to accelerate development of $\mathrm{HCV}$ vaccines.

\section{AUTHOR CONTRIBUTIONS}

YT, JZ, and DL drafted the manuscript; QL performed bioinformatics analysis.

\section{FUNDING}

We acknowledge the funding support from the National Natural Science Foundation of China (31670172) and the Chinese National 973 Program (2015CB554300) to JZ, the National Natural Science Foundation of China (31770189) to YT, and Chinese Academy of Sciences (100 talent program and grant 153211KYSB20160001), the Ministry of Science and Technology international grant (2016YFE133500), and the Shanghai municipality 1000 Talent program to DL.

8. Li Y, Modis Y. A novel membrane fusion protein family in Flaviviridae? Trends Microbiol (2014) 22:176-82. doi:10.1016/j.tim.2014.01.008

9. Keck ZY, Sung VM, Perkins S, Rowe J, Paul S, Liang TJ, et al. Human monoclonal antibody to hepatitis $\mathrm{C}$ virus $\mathrm{E} 1$ glycoprotein that blocks virus attachment and viral infectivity. J Virol (2004) 78:7257-63. doi:10.1128/ JVI.78.13.7257-7263.2004

10. Dubuisson J, Hsu HH, Cheung RC, Greenberg HB, Russell DG, Rice CM. Formation and intracellular localization of hepatitis $\mathrm{C}$ virus envelope glycoprotein complexes expressed by recombinant vaccinia and Sindbis viruses. J Virol (1994) 68:6147-60.

11. Mesalam AA, Desombere I, Farhoudi A, Van Houtte F, Verhoye L, Ball J, et al. Development and characterization of a human monoclonal antibody targeting the $\mathrm{N}$-terminal region of hepatitis $\mathrm{C}$ virus envelope glycoprotein $\mathrm{E} 1$. Virology (2018) 514:30-41. doi:10.1016/j.virol.2017.10.019

12. Meunier JC, Russell RS, Goossens V, Priem S, Walter H, Depla E, et al. Isolation and characterization of broadly neutralizing human monoclonal antibodies to the el glycoprotein of hepatitis C virus. J Virol (2008) 82:966-73. doi:10.1128/ JVI.01872-07

13. Kong L, Kadam RU, Giang E, Ruwona TB, Nieusma T, Culhane JC, et al. Structure of hepatitis $\mathrm{C}$ virus envelope glycoprotein E1 antigenic site 
314-324 in complex with antibody IGH526. J Mol Biol (2015) 427:2617-28. doi:10.1016/j.jmb.2015.06.012

14. Yusim K, Richardson R, Tao N, Dalwani A, Agrawal A, Szinger J, et al. Los alamos hepatitis C immunology database. Appl Bioinformatics (2005) 4: 217-25. doi:10.2165/00822942-200504040-00002

15. Crooks GE, Hon G, Chandonia JM, Brenner SE. WebLogo: a sequence logo generator. Genome Res (2004) 14:1188-90. doi:10.1101/gr.849004

16. Goffard A, Dubuisson J. Glycosylation of hepatitis $C$ virus envelope proteins. Biochimie (2003) 85:295-301. doi:10.1016/S0300-9084(03)00004-X

17. Meunier JC, Fournillier A, Choukhi A, Cahour A, Cocquerel L, Dubuisson J, et al. Analysis of the glycosylation sites of hepatitis C virus (HCV) glycoprotein E1 and the influence of E1 glycans on the formation of the HCV glycoprotein complex. J Gen Virol (1999) 80(Pt 4):887-96. doi:10.1099/0022-1317-80-4-887

18. Zhang M, Gaschen B, Blay W, Foley B, Haigwood N, Kuiken C, et al. Tracking global patterns of $\mathrm{N}$-linked glycosylation site variation in highly variable viral glycoproteins: HIV, SIV, and HCV envelopes and influenza hemagglutinin. Glycobiology (2004) 14:1229-46. doi:10.1093/glycob/cwh106

19. Goffard A, Callens N, Bartosch B, Wychowski C, Cosset FL, Montpellier C, et al. Role of $\mathrm{N}$-linked glycans in the functions of hepatitis $\mathrm{C}$ virus envelope glycoproteins. J Virol (2005) 79:8400-9. doi:10.1128/JVI.79.13.8400-8409.2005

20. Helle F, Vieyres G, Elkrief L, Popescu CI, Wychowski C, Descamps V, et al. Role of $\mathrm{N}$-linked glycans in the functions of hepatitis $\mathrm{C}$ virus envelope proteins incorporated into infectious virions. J Virol (2010) 84:11905-15. doi:10.1128/ JVI.01548-10

21. Fournillier A, Wychowski C, Boucreux D, Baumert TF, Meunier JC, Jacobs D, et al. Induction of hepatitis C virus E1 envelope protein-specific immune response can be enhanced by mutation of N-glycosylation sites. J Virol (2001) 75:12088-97. doi:10.1128/JVI.75.24.12088-12097.2001

22. Ren Y, Min YQ, Liu M, Chi L, Zhao P, Zhang XL. N-glycosylation-mutated HCV envelope glycoprotein complex enhances antigen-presenting activity and cellular and neutralizing antibody responses. Biochim Biophys Acta (2016) 1860:1764-75. doi:10.1016/j.bbagen.2015.08.007

23. El Omari K, Iourin O, Kadlec J, Sutton G, Harlos K, Grimes JM, et al. Unexpected structure for the $\mathrm{N}$-terminal domain of hepatitis $\mathrm{C}$ virus envelope glycoprotein E1. Nat Commun (2014) 5:4874. doi:10.1038/ncomms5874

24. Castelli M, Clementi N, Pfaff J, Sautto GA, Diotti RA, Burioni R, et al. A biologically-validated HCV E1E2 heterodimer structural model. Sci Rep (2017) 7(1):214. doi:10.1038/s41598-017-00320-7

25. Freedman H, Logan MR, Hockman D, Koehler Leman J, Law JL, Houghton M. Computational prediction of the heterodimeric and higher-order structure of gpE1/gpE2 envelope glycoproteins encoded by hepatitis C virus. J Virol (2017) 91(8):e02309-16. doi:10.1128/JVI.02309-16

26. Vieyres G, Thomas X, Descamps V, Duverlie G, Patel AH, Dubuisson J. Characterization of the envelope glycoproteins associated with infectious hepatitis C virus. J Virol (2010) 84:10159-68. doi:10.1128/JVI.01180-10

27. Wahid A, Helle F, Descamps V, Duverlie G, Penin F, Dubuisson J. Disulfide bonds in hepatitis $\mathrm{C}$ virus glycoprotein $\mathrm{E} 1$ control the assembly and entry functions of E2 glycoprotein. J Virol (2013) 87:1605-17. doi:10.1128/ JVI.02659-12

28. Ryser HJ, Levy EM, Mandel R, DiSciullo GJ. Inhibition of human immunodeficiency virus infection by agents that interfere with thiol-disulfide interchange upon virus-receptor interaction. Proc Natl Acad Sci U S A (1994) 91:4559-63. doi:10.1073/pnas.91.10.4559

29. Wallin M, Ekstrom M, Garoff H. Isomerization of the intersubunit disulphidebond in Env controls retrovirus fusion. EMBO J (2004) 23:54-65. doi:10.1038/sj.emboj.7600012

30. Fenouillet E, Lavillette D, Loureiro S, Krashias G, Maurin G, Cosset FL, et al. Contribution of redox status to hepatitis $\mathrm{C}$ virus $\mathrm{E} 2$ envelope protein function and antigenicity. J Biol Chem (2008) 283:26340-8. doi:10.1074/jbc. M805221200

31. McCaffrey K, Boo I, Tewierek K, Edmunds ML, Poumbourios P, Drummer HE. Role of conserved cysteine residues in hepatitis $C$ virus glycoprotein e2 folding and function. J Virol (2012) 86:3961-74. doi:10.1128/ JVI.05396-11

32. Spadaccini R, D’Errico G, D’Alessio V, Notomista E, Bianchi A, Merola M, et al. Structural characterization of the transmembrane proximal region of the hepatitis C virus E1 glycoprotein. Biochim Biophys Acta (2010) 1798:344-53. doi:10.1016/j.bbamem.2009.10.018
33. Op De Beeck A, Montserret R, Duvet S, Cocquerel L, Cacan R, Barberot B, et al. The transmembrane domains of hepatitis $\mathrm{C}$ virus envelope glycoproteins E1 and E2 play a major role in heterodimerization. J Biol Chem (2000) 275:31428-37. doi:10.1074/jbc.M003003200

34. Falson P, Bartosch B, Alsaleh K, Tews BA, Loquet A, Ciczora Y, et al. Hepatitis $\mathrm{C}$ virus envelope glycoprotein E1 forms trimers at the surface of the virion. J Virol (2015) 89:10333-46. doi:10.1128/JVI.00991-15

35. Cocquerel L, Meunier JC, Pillez A, Wychowski C, Dubuisson J. A retention signal necessary and sufficient for endoplasmic reticulum localization maps to the transmembrane domain of hepatitis C virus glycoprotein E2. J Virol (1998) 72:2183-91.

36. Deleersnyder V, Pillez A, Wychowski C, Blight K, Xu J, Hahn YS, et al. Formation of native hepatitis C virus glycoprotein complexes. J Virol (1997) 71:697-704.

37. Ciczora Y, Callens N, Montpellier C, Bartosch B, Cosset FL, Op de Beeck A, et al. Contribution of the charged residues of hepatitis $\mathrm{C}$ virus glycoprotein $\mathrm{E} 2$ transmembrane domain to the functions of the E1E2 heterodimer. J Gen Virol (2005) 86:2793-8. doi:10.1099/vir.0.81140-0

38. Michalak JP, Wychowski C, Choukhi A, Meunier JC, Ung S, Rice CM, et al. Characterization of truncated forms of hepatitis $\mathrm{C}$ virus glycoproteins. J Gen Virol (1997) 78(Pt 9):2299-306. doi:10.1099/0022-1317-78-9-2299

39. Cocquerel L, Wychowski C, Minner F, Penin F, Dubuisson J. Charged residues in the transmembrane domains of hepatitis $\mathrm{C}$ virus glycoproteins play a major role in the processing, subcellular localization, and assembly of these envelope proteins. J Virol (2000) 74:3623-33. doi:10.1128/JVI.74.8.3623-3633.2000

40. Patel J, Patel AH, McLauchlan J. The transmembrane domain of the hepatitis $\mathrm{C}$ virus E2 glycoprotein is required for correct folding of the E1 glycoprotein and native complex formation. Virology (2001) 279:58-68. doi:10.1006/ viro. 2000.0693

41. Ciczora Y, Callens N, Penin F, Pecheur EI, Dubuisson J. Transmembrane domains of hepatitis $\mathrm{C}$ virus envelope glycoproteins: residues involved in E1E2 heterodimerization and involvement of these domains in virus entry. J Virol (2007) 81:2372-81. doi:10.1128/JVI.02198-06

42. Baktash Y, Madhav A, Coller KE, Randall G. Single particle imaging of polarized hepatoma organoids upon hepatitis $C$ virus infection reveals an ordered and sequential entry process. Cell Host Microbe (2018) 23:382-394e5. doi:10.1016/j.chom.2018.02.005

43. Petracca R, Falugi F, Galli G, Norais N, Rosa D, Campagnoli S, et al. Structurefunction analysis of hepatitis C virus envelope-CD81 binding. J Virol (2000) 74:4824-30. doi:10.1128/JVI.74.10.4824-4830.2000

44. Scarselli E, Ansuini H, Cerino R, Roccasecca RM, Acali S, Filocamo G, et al. The human scavenger receptor class $B$ type I is a novel candidate receptor for the hepatitis C virus. EMBO J (2002) 21:5017-25. doi:10.1093/emboj/cdf529

45. Douam F, Dao Thi VL, Maurin G, Fresquet J, Mompelat D, Zeisel MB, et al. Critical interaction between E1 and E2 glycoproteins determines binding and fusion properties of hepatitis C virus during cell entry. Hepatology (2014) 59:776-88. doi:10.1002/hep.26733

46. Hopcraft SE, Evans MJ. Selection of a hepatitis C virus with altered entry factor requirements reveals a genetic interaction between the E1 glycoprotein and claudins. Hepatology (2015) 62:1059-69. doi:10.1002/hep.27815

47. Haddad JG, Rouille Y, Hanoulle X, Descamps V, Hamze M, Dabboussi F, et al. Identification of novel functions for hepatitis $\mathrm{C}$ virus envelope glycoprotein E1 in virus entry and assembly. J Virol (2017) 91(8):e00048-17. doi:10.1128/ JVI.00048-17

48. Mazumdar B, Banerjee A, Meyer K, Ray R. Hepatitis C virus E1 envelope glycoprotein interacts with apolipoproteins in facilitating entry into hepatocytes. Hepatology (2011) 54:1149-56. doi:10.1002/hep.24523

49. Lee JY, Acosta EG, Stoeck IK, Long G, Hiet MS, Mueller B, et al. Apolipoprotein E likely contributes to a maturation step of infectious hepatitis $C$ virus particles and interacts with viral envelope glycoproteins. J Virol (2014) 88:12422-37. doi:10.1128/JVI.01660-14

50. Cheng JJ, Li JR, Huang MH, Ma LL, Wu ZY, Jiang CC, et al. CD36 is a coreceptor for hepatitis C virus E1 protein attachment. Sci Rep (2016) 6 21808. doi:10.1038/srep21808

51. Tscherne DM, Jones CT, Evans MJ, Lindenbach BD, McKeating JA, Rice CM. Time- and temperature-dependent activation of hepatitis C virus for low-pH-triggered entry. J Virol (2006) 80:1734-41. doi:10.1128/JVI.80. 4.1734-1741.2006 
52. Khan AG, Whidby J, Miller MT, Scarborough H, Zatorski AV, Cygan A, et al. Structure of the core ectodomain of the hepatitis $\mathrm{C}$ virus envelope glycoprotein 2. Nature (2014) 509:381-4. doi:10.1038/nature13117

53. Kong L, Giang E, Nieusma T, Kadam RU, Cogburn KE, Hua Y, et al. Hepatitis C virus E2 envelope glycoprotein core structure. Science (2013) 342:1090-4. doi:10.1126/science. 1243876

54. Li Y, Wang J, Kanai R, Modis Y. Crystal structure of glycoprotein E2 from bovine viral diarrhea virus. Proc Natl Acad Sci U S A (2013) 110:6805-10. doi:10.1073/pnas.1300524110

55. Garry RF, Dash S. Proteomics computational analyses suggest that hepatitis $C$ virus E1 and pestivirus E2 envelope glycoproteins are truncated class II fusion proteins. Virology (2003) 307:255-65. doi:10.1016/S0042-6822(02)00065-X

56. Lavillette D, Pecheur EI, Donot P, Fresquet J, Molle J, Corbau R, et al. Characterization of fusion determinants points to the involvement of three discrete regions of both E1 and E2 glycoproteins in the membrane fusion process of hepatitis C virus. J Virol (2007) 81:8752-65. doi:10.1128/JVI.02642-06

57. Tong Y, Chi X, Yang W, Zhong J. Functional analysis of hepatitis C virus (HCV) envelope protein E1 using a trans-complementation system reveals a dual role of a putative fusion peptide of E1 in both HCV entry and morphogenesis. J Virol (2017) 91(7):e02468-16. doi:10.1128/JVI.02468-16

58. Perin PM, Haid S, Brown RJ, Doerrbecker J, Schulze K, Zeilinger C, et al. Flunarizine prevents hepatitis $\mathrm{C}$ virus membrane fusion in a genotypedependent manner by targeting the potential fusion peptide within E1. Hepatology (2016) 63:49-62. doi:10.1002/hep.28111

59. Li HF, Huang CH, Ai LS, Chuang CK, Chen SS. Mutagenesis of the fusion peptide-like domain of hepatitis $\mathrm{C}$ virus $\mathrm{E} 1$ glycoprotein: involvement in cell fusion and virus entry. J Biomed Sci (2009) 16:89. doi:10.1186/1423-0127-16-89

60. Drummer HE, Boo I, Poumbourios P. Mutagenesis of a conserved fusion peptide-like motif and membrane-proximal heptad-repeat region of hepatitis $\mathrm{C}$ virus glycoprotein E1. J Gen Virol (2007) 88:1144-8. doi:10.1099/vir.0.82567-0

61. Lombana L, Ortega-Atienza S, Gomez-Gutierrez J, Yelamos B, Peterson DL, Gavilanes F. The deletion of residues 268-292 of E1 impairs the ability of HCV envelope proteins to induce pore formation. Virus Res (2016) 217:63-70. doi:10.1016/j.virusres.2016.02.009
62. DuBois RM, Vaney MC, Tortorici MA, Kurdi RA, Barba-Spaeth G, Krey T, et al. Functional and evolutionary insight from the crystal structure of rubella virus protein E1. Nature (2013) 493:552-6. doi:10.1038/nature11741

63. Kielian M. Mechanisms of virus membrane fusion proteins. Annu Rev Virol (2014) 1:171-89. doi:10.1146/annurev-virology-031413-085521

64. Douam F, Fusil F, Enguehard M, Dib L, Nadalin F, Schwaller L, et al. A protein coevolution method uncovers critical features of the Hepatitis C Virus fusion mechanism. PLoS Pathog (2018) 14:e1006908. doi:10.1371/journal. ppat.1006908

65. Stapleford KA, Lindenbach BD. Hepatitis C virus NS2 coordinates virus particle assembly through physical interactions with the E1-E2 glycoprotein and NS3-NS4A enzyme complexes. J Virol (2011) 85:1706-17. doi:10.1128/ JVI.02268-10

66. Ma Y, Anantpadma M, Timpe JM, Shanmugam S, Singh SM, Lemon SM, et al. Hepatitis C virus NS2 protein serves as a scaffold for virus assembly by interacting with both structural and nonstructural proteins. J Virol (2011) 85:86-97. doi:10.1128/JVI.01070-10

67. Li R, Qin Y, He Y, Tao W, Zhang N, Tsai C, et al. Production of hepatitis $\mathrm{C}$ virus lacking the envelope-encoding genes for single-cycle infection by providing homologous envelope proteins or vesicular stomatitis virus glycoproteins in trans. J Virol (2011) 85:2138-47. doi:10.1128/JVI.02313-10

Conflict of Interest Statement: The authors declare that the research was conducted in the absence of any commercial or financial relationships that could be construed as a potential conflict of interest.

Copyright (c) 2018 Tong, Lavillette, Li and Zhong. This is an open-access article distributed under the terms of the Creative Commons Attribution License (CC BY). The use, distribution or reproduction in other forums is permitted, provided the original author(s) and the copyright owner are credited and that the original publication in this journal is cited, in accordance with accepted academic practice. No use, distribution or reproduction is permitted which does not comply with these terms. 